were exceptions to it. The jury at once acted on the hint by acquitting the prisoner on the ground of insanity. Many of our judyes would not hesitale nowadays to treat the orthodox test of criminal responsibility in mental disease with equal freedom. But Lord Blackburn's "departure" was taken about a quarter of a century ago, when the authority of McNaghten's case was far more unchallenged than it is at the present day.

\title{
Dr. ROBert Lawson.
}

We regret to have to record the death of Dr. Robert Lawson, Deputy-Commissioner in Lunacy for Scotland, after a valued service of eighteen years in that capacity.

Dr. Lawson was born in Kirriemuir, and, in common with other members of his family, early showed a marked literary capacity. Before entering on the study of medicine, indeed, he had engaged in journalism, and throughout his life he was a devoted student of literature. Dr. Lawson took the degree of M.B. at the University of Edinburgh in 1871, and M.D. in 1888. In his student days he was well known as the maker of witty songs and the retailer of humorous stories, and his kindly, generous nature is fresh in the recollection of many faithful friends. Professor Iaycock selected him as his class assistant in 1871-2, and imbued him with the shrewd and original thinking for which the chair of medicine was then celebrated.

After practising for a short time in London, Dr. Lawson became Assistant Medical Officer at the West Riding Asylum, then at the zenilh of its fame, under the direction of Sir James Crichton Browne, who valued him as one of the ablest and most agreeable assistants he ever had. His contributions to scientific medicine at that period, particularly his notable research into the "Action of Hyoscyamine," showed that Dr. Lawson combined high literary culture with scientific insight and approved method. For a short time he was Medical Superintendent of Wonford House Asylum, Exeter, from which appointment he was promoted to the onerous and responsible duties which he fulfilled until quite recently. As Deputy-Commissioner, his work led him to the most remote parts of Scotland, where he had to visit and report upon the boarded-out cases of lunacy. Quite recently the writer of these lines heard of a touching instance of his unrecorded kindliness in dealing with a somewhat troublesome case, and there can be no doubt that his generous presence will be greatly missed in many a humble home in the far north. In his annual reports Dr. Lawson gavo graphic accounts of his journeyings, and strong, unprejudiced support to a mode of lunacy administration which has lately passed under some adverse and ill-informed criticism. IIis evidence is all the more valuable in having been presented by one who undertook the duties of Deputy-Commissioner after great experience and with a large mind.

His loss is deeply regretted by a wide circle of friends, official and personal -friends who had the advantage of knowing him in private life and recognising that he had it in his power to make a distinguished name. But he was modest and unambitious, and preferred to pursue a quiet bye-path in the great world, illumined by intimate acquaintance with the master minds of literature, and intent upon performing the work he had to do with the kindly care and sympathy of his rich nature.

\section{Dr. Henri Contagne.}

The death of Dr. Contagne, the medico-legal expert and lecturer on forensic medicine at Lyons, should not be allowed to pass wholely unrecorded here, since he was always warmly interested in English medical science, and especially in all that concerned the treatment and study of criminals. He was Professor Iacassagne's chief co-worker in the great French medico-legal centre, and his 